\title{
Simulation and research of cylindrical broach structures stress-strain state in solidworks system
}

\author{
Svetlana Lukina ${ }^{1, *}$, Anna Yakovleva $^{2}$ and Olga Zimovets ${ }^{1}$ \\ ${ }^{1}$ Moscow State Technological University “STANKIN”, 3a Vadkovsky, Moscow 127055, Russian \\ Federation \\ ${ }^{2}$ Bauman Moscow State Technical University, 2nd Baumanskaya st., 5, Moscow, 105005, Russian \\ Federation
}

\begin{abstract}
The authors considered a methodology for the automated design of cylindrical broach structures consisting of the following stages: forming a 3D-parametric geometrical broach image, assessing a broach structure stress-strain state during operation. The paper presents the results of software implementation of the algorithm for forming a broach structure parametric model from 3D-geometrical prototypes in the system Solidworks. To assess a stress-strain state of tools with the numerical method of finite elements in Solidworks Simulation, the authors formed an analytical design model taking into account strain of geometric prototypes. A series of numerical experiments was aimed at researching a stress-strain state of broach teeth under cutting forces action. According to the results of numerical experiments, by means of the least square method the authors obtained analytical expressions to estimate the influence of geometrical and design parameters of the broach teeth structure on elastic displacements of cutting edges vertice and equivalent stresses of the most loaded teeth components. The authors developed recommendations on the change of the teeth section parameters allowing for the extension of the broach structure operation life and reducing the tool life consumption for the batch of parts.
\end{abstract}

\section{Introduction}

The relevant task of modern industrial facilities is the adoption of advanced industrial processes allowing for a significant labor efficiency. One of such metal cutting processes is broaching which is especially efficient in the conditions of large-scale and serial production. Broaching is applied in various areas of engineering at the cutting of various materials. This process provides for the consistent production of high-precision parts with a low surface roughness [1-5].

A broach structure is a complex design tool difficult to manufacture, which combines rough, transition, finishing and calibrating parts, each of which is characterized by its own

\footnotetext{
*Corresponding author: lukina_sv@mail.ru
} 
structural and geometrical parameters and operates within a definite range of tooth increment. The problem of selecting an efficient tool design is complex and multidimensional, it requires the optimization of multiple industrial, design and operation factors [1, 6- 17].

The key factors defining the strength, stiffness and long life cycle of the broach structure are structural and geometrical parameters of teeth: step $t$, chip groove depth (tooth height) $h$, length of a rear side $b$, tooth thickness $g$ with average height, face $\gamma$ and back $\alpha$ angles, radii of chip groove rounding-off $r$ and tooth back radius $R$, cutting edge form (availability of chip separation fillets or grooves) [1,7-9, 19-21 ].

At present the teeth form and dimensions in the axial section are standardized in literature and are defined in relation to the set step and in compliance to the condition of the chip groove filling degree. The dimensions $h, b, r, R$ in the tool axial section in terms of stiffness are not justified [1, 10-12, 14-18].

The research purpose is to develop the automated design methodology for cylindrical broach structures in the system Solidworks.

To achieve the set objective, the following research tasks are stated in the paper: to form a total of structural and geometrical parameters characterizing the cylindrical broach structure; to develop broach image from 3D geometrical prototypes in the system Solidworks; to research a stress-strain state of broach teeth under cutting forces action in the system Solidworks Simulation; to develop recommendations on the change of the teeth section parameters allowing for the extension of the broach structure operation life and reducing the tool life consumption for the batch of parts.

\section{Problem settlement}

Guaranteeing a high quality of design solutions is possible by means of integrated systems allowing for design automation and broach structure calculation. The authors suggest a methodology for the automated design of cylindrical broach structures consisting of the following stages: forming a 3D-parametric geometrical broach image, assessing a broach structure stress-strain state during operation.

Forming a set of parametric 3D-geometrical prototypes of broach structural components, such as front and rear shanks, front and rear guideways, adapter sleeve and journal, section of transition, finishing and calibrating teeth, facilitates a significant reduction of the labour intensity of tool designing in CAD systems.

Assessment of the broach structure stress-strain state in the process of operation allows justifying and setting the parameters of the teeth section in terms of their strength and stiffness.

\section{Forming a parametric 3D-geometirical image of the broach structure}

The authors of the paper chose the system Solidworks as a basic integrated automated system. This system helps to avoid possible tool design and manufacture errors at the stage of drawing design study, evaluate the stress-strain state and optimize the tool structure by means of built-in subsystens and programming macros. To form the broach structure image in the system solidworks, the authors formed a set of parametric 3D-geometrical prototypes of broach structural elements.

Simulation of the procedures for forming and selecting structural component layouts of the broach structure operating section was conducted on the basis of the analysis of a directed graph model. Each graph vertice and edge define some tool structure part, its 
structural component or the structure part or structural component parameters. A set of options of structural component layout of the broach structure operation part is represented by a set of graph traversals [17-21].

Geometrical prototypes of the broach tail and operation parts are parametrized for the processing diameters in the range $10-50 \mathrm{~mm}$ with the tooth step 4-32 mm. Estimated parametrization of the structural components of the broach structure operation part combining rough, transition, finishing and calibrating teeth was implemented with the help of the Visual Basic language allowing for making a software integration with the system solidworks. The macros developed make it possible to calculate key structural dimensions of rough, transition and calibrating teeth; choose the number of teeth in a group and the allowance cutting pattern; calculate the number and location of chip separation components.

The developed dimensional and parametric geometrical prototypes of the structural components of the operating part and internal broach in general are presented in Figure 1 and Figure 2, correspondingly. The broach image formed in a 3D-form allows authors to study and assess the stress state of both a single tooth or teeth section and a whole broach part.

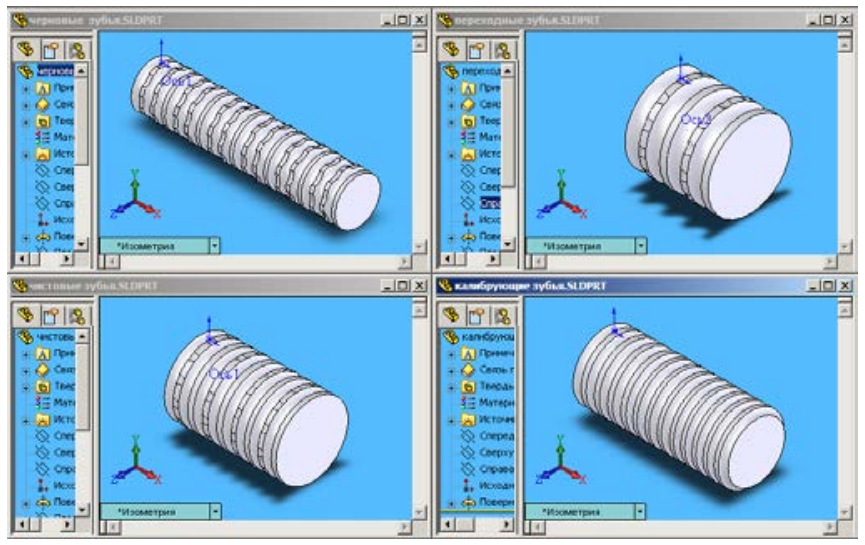

Fig. 1. Dimensional parametric 3D-geometrical prototypes of structural components of an operation part of the broach structure.

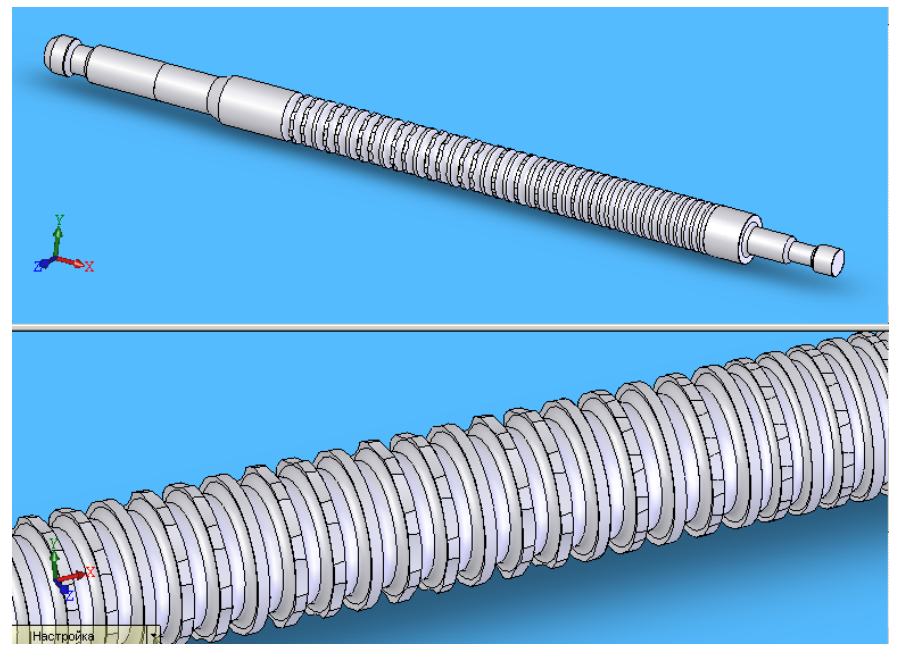

Fig. 2. Generalized design of a cylindrical broach structure. 


\section{Research of stress-strain state of broach teeth}

In the paper the authors selected the geometrical and structural parameters of the broach structure operating part on the basis of the research of the tool stress-strain state under cutting forces at penetration and in the process of the established cutting procedure.

Under the action of cutting forces the broach teeth are subject to Hooke deformation (elastic strain) resulting in the change of their form and geometrical dimensions, the broach body loses its stability causing the tool axis deviation.

At tool penetration no chip cutting is performed as the tooth is located outside the part. Consequently, the tooth is subject only to the axial component of cutting force. The broach structure tooth is deformed both axially and radially. As a result the tooth cutting edge deviation occurs and the actula tooth increment changes. Cutting starts after chip formation. A tooth is located inside a part under the action of axial and radial components of cutting forces.

Cutting forces in various points of the cutting edge can change at tooth movement inside a workpiece due to a non-constant cutting depth, workpiece material hardness and other causes. To provide the possibility of teeth deformation analytical calculation, the paper considers an ideal case of broaching when the value of cutting force at the cutting edge is assumed to be constant.

Theoretical research were conducted by means of a numerical method of finite elements in Solidworks Simulation for broach structures manufactured of high-speed steel and heat treated up to the hardness 62 - 64 HRC.

The material was assumed to be isotropic and abiding to the generalized Hooke's law. Thermally induced stresses were not taken into account because of small cutting speeds at internal broaching. The experiments were aimed at determining the values of axial and radial movements of cutting edge vertices and stresses in the section hazardous area under cutting force action. When making a design model, the authors assumed that the broach tooth operates as a fixed beam with a variable section.

The values of the axial cutting force component were calculated according to the expression taking into account a real length of cutting edges of the teeth simultaneously involved in the operation:

$$
P_{o}=q\left(\pi d / z_{c}-0.123 d^{1.5} / z_{c}{ }^{0.67}\right) z_{i}
$$

where $q$ - unit cutting force per $1 \mathrm{~mm}$ of the tooth cutting edge length, $d$ - tooth diameter, $\mathrm{mm}, z_{c}$ - number of teeth in a section, $z_{i}$ - the highest number of simultaneously operating teeth.

The calculations demonstrated that the values of the highest axial and radial strains during cutting are 2.5,..,3 times less than those observed at the stage of tooth penetration into a workpiece.

I.e., radial forces occurring during cutting on the side of the processed workpiece reduce the strains in the tooth body thus unloading it. Thus, in relation to the stress-strain state, in the process of steady-state cutting the cutting blade is under more favorable conditions comparing to the stage of the tooth penetration into a workpiece.

On the basis of the aforementioned the authors concluded that to identify optimal tool teeth in terms of stiffness and strength, it is necessary and sufficient to study their stressstrain state at the workpiece penetration state.

The theoretical research results are presented in the form of arrays of node and stresses movements relating to the finite component model elements; stereograms of strains, movements and stresses formed in Solidwoks Simulation (Figure 3). 


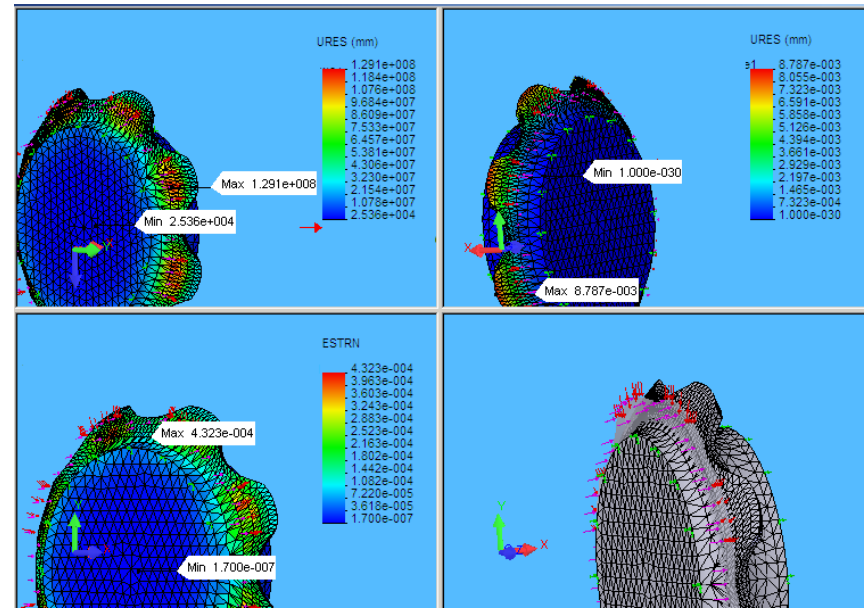

Fig. 3. Stereograms of strains, movements and stresses of the first broach structure rough teeth formed in Solidworks Simulation.

The calculations showed that the highest axial and radial movements occur at the tooth penetration in a workpiece. Increasing cutting force due to the wear of teeth cutting edges facilitates the increase in axial and radial movements by $12 \div 15 \%$ on average.

The movements of the cutting edge vertice depend on the stiffness of the tooth section changing during re-sharperning. The nature of stresses in the studied section depends on the tooth section parameters and the cutting force value.

Compressing strain occurs in the components located along the rear side and the tooth radius back, and the highest compression is observed in the components at the cutting edge vertice. Tensile stresses are concentrated along the front surface of the tooth section while the highest of them occur in the front surface parts with average depth. For a large number of instrument steel types tensile stresses are the most hazardous ones, that is why the tooth break will likely occur along the line of the highest main tensile stresses.

According to the results of numerical experiments, by means of the least square method the authors obtained analytical expressions to estimate the influence of geometrical and design parameters of the broach teeth structure on elastic displacements of cutting edges point and equivalent stresses of the most loaded teeth components:

$$
\begin{aligned}
& U=A b^{a} \gamma^{f} S_{z}{ }^{d} h^{i} R^{j} r^{k} t^{m} \alpha^{n} K_{w} \\
& \sigma=B b^{e} \gamma^{c} S_{z}{ }^{g} h^{l} R^{p} r^{z} K_{w}
\end{aligned}
$$

where $b$ - rear side length, $\gamma$ - face angle, $S_{z}$ - tooth increment, $h$ - teeth height, $R$ tooth back radius, $r$-radius of chip groove rounding-off, $t$-tooth step, $\alpha$ - back angle, $K_{w}-$ teeth wear factor [17].

A constant factor and exponential factors at geometrical and structural parameters in the expressions (2) and (3) are calculated by means of approximation of numerical data of the estimate of the broach teeth stress-strain state at the stage of their penetration into a workpiece (Table 1, 2).

The developed models adequacy is justified by the comparison conducted for theoretical research and the results of natural experiments carried out at the broach structures with identical structural and geometrical parameters [3]. 
Table 1. A constant factor and exponential factors at geometrical and structural parameters in the expressions (2).

\begin{tabular}{|c|c|c|c|c|c|c|c|c|c|}
\hline \multirow{2}{*}{$\begin{array}{c}\text { Tooth } \\
\text { type }\end{array}$} & $\mathbf{A}$ & $\mathbf{a}$ & f & d & $\mathbf{i}$ & $\mathbf{j}$ & $\mathbf{k}$ & $\mathbf{m}$ & $\mathbf{n}$ \\
\hline & \multicolumn{9}{|c|}{ Axial movements, Ux, mm } \\
\hline Rough part & 0.0030 & -0.87 & 0.45 & 0.85 & \multirow{3}{*}{1.53} & \multirow{3}{*}{2,3} & \multirow{3}{*}{$-0,006$} & \multirow{3}{*}{-0.006} & \multirow{3}{*}{0.03} \\
\hline $\begin{array}{l}\text { Finishing } \\
\text { part }\end{array}$ & 0.0008 & -0.86 & 0.18 & 0.57 & & & & & \\
\hline $\begin{array}{l}\text { Calibrating } \\
\text { part }\end{array}$ & 0.0004 & -0.87 & 0.18 & 0.56 & & & & & \\
\hline & \multicolumn{9}{|c|}{ Radial movements, Uy, mm } \\
\hline Rough part & 0.030 & -0.844 & 0.70 & 0.82 & \multirow{3}{*}{1,3} & \multirow{3}{*}{-1.3} & \multirow{3}{*}{-0.112} & \multirow{3}{*}{-0.23} & \multirow{3}{*}{0.03} \\
\hline $\begin{array}{l}\text { Finishing } \\
\text { part }\end{array}$ & 0.009 & -0.768 & 0.39 & 0.57 & & & & & \\
\hline $\begin{array}{l}\text { Calibrating } \\
\text { part }\end{array}$ & 0.004 & -0.764 & 0.39 & 0.55 & & & & & \\
\hline
\end{tabular}

Table 2. A constant factor and exponential factors at geometrical and structural parameters in the expressions (3).

\begin{tabular}{|c|c|c|c|c|c|c|c|}
\hline \multirow[t]{2}{*}{ Tooth type } & B & e & C & g & I & $\mathbf{j}$ & $\mathbf{k}$ \\
\hline & \multicolumn{7}{|c|}{$\begin{array}{c}\text { Equivalent stresses of the most loaded teeth components at } \\
\text { the cutting edge vertice, MPa }\end{array}$} \\
\hline Rough part & 2700 & \multirow[b]{2}{*}{0.215} & \multirow[b]{2}{*}{0.122} & 0.93 & \multirow[b]{2}{*}{-0.51} & \multirow[b]{2}{*}{ - } & \multirow[b]{2}{*}{ - } \\
\hline $\begin{array}{l}\text { Finishing and Calibrating } \\
\text { parts }\end{array}$ & 900 & & & 1.09 & & & \\
\hline & \multicolumn{7}{|c|}{$\begin{array}{c}\text { Equivalent stresses of the most loaded teeth components in } \\
\text { the front surface parts with average depth, MPa }\end{array}$} \\
\hline Rough part & 10300 & \multirow[b]{2}{*}{1.083} & \multirow[b]{2}{*}{0.480} & 0.65 & \multirow[b]{2}{*}{0.55} & \multirow[b]{2}{*}{-1.49} & \multirow[b]{2}{*}{-0.30} \\
\hline $\begin{array}{l}\text { Finishing and Calibrating } \\
\text { parts }\end{array}$ & 3815 & & & 0.71 & & & \\
\hline
\end{tabular}

\section{Conclusions}

A series of conducted numerical experiments with the broach structures of various diameters demonstrated the methodology operability in terms of the choice of optimum tool structures with single and group cutting patterns.

The conducted research allowed:

- justifying the permissible value of abrasion from internal broach front surfaces within $0.7 \mathrm{~b}$;

- limiting the tooth increment value to $0.3 \mathrm{~mm}$;

- justifying the reduction in the section depth to $0.35 t$, increasing the radii of chip groove rounding-off up to $0.6 \mathrm{~h}$ and tooth back to $0.8 \mathrm{t}$ with the purpose of increasing the stiffness of finishing and calibration teeth of a new broach structure and reducing the broached hole division;

-identifying the reserves of increasing front angles up to 20-250 at re-sharpened finishing and calibrating teeth to decrease their stiffness and compensate the diameter decrease at restoration.

The proposed recommendations on changing the parameters of teeth section allow increasing the broach operation life by 1.25 - 1.4 times, reducing the tool life consumption by $20 \%$ and decrease the broaching net cost by $25-30 \%$.

The developed complex allows improving the efficiency of broach design due to the structure automated synthesis from parametric 3D-geometrical prototypes of structural 
components and selection of the teeth section parameters with the consideration of their stress-strain state.

The expansion of the invented methodology for other types of broaches will provide for its further development.

\section{References}

1. D.K. Margulis, M.M. Tverskoy, V.N. Ashihmin, Protjazhki dlja obrabotki otverstij, (Mashinostroenie, Moscow, 1986)

2. C. Monday, Broaching, (The Machinery Publishing Co., London, 1960)

3. Ni, J.; Li, B.; Xu, J. Investigation on broaching performance and unloading mechanism of micro-textured broach, International Journal of Advance Manufacturing Technoljgy, 86, pp 2449-2458 (2016)

4. A.P. Kuznetsov, M. G. Kosov, Structural precision of metal-cutting machines, Russian Engineering Research, 32(5-6), pp 482-490 (2012)

5. P. Gilormini, E. Felder, A Comparative Analysis of Three Machining Processes: Broaching, Tapping and Slotting, Annals of the CIRP, 33/1, pp 19-22 (1984)

6. S. Hagglund, New Procedure for Optimizing Cutting Data for General Turning, Proceedings of the Institution of Mechanical Engineers, 217/B, pp 349-362 (2003)

7. P.J. Arrazola, T. Özel, D. Umbrello, M. Davies, I.S. Jawahir, Recent advances in modelling of metal machining processes, CIRP Annals-Manufacturing Technology, 62(2), pp 695-718 (2013)

8. R.H. Todd, D.K. Alltn, L. Alting, Manufacturing Processes Reference Guide, (Industrial Press Inc., Ney York, 1994)

9. O. Ozturk, M. Sc. Thesis, Modelling of Broaching Process, Industrial Engineering, (Sabanci University Publ, Istanbul, 2003)

10. P. Mason, Computerized cutting-tool management, American machine and automatic manufacturing, 5, pp.106-113 (1986)

11. A. Hosseini, H.A. Kishawy, On the Optimized Design of Broaching Tools, Journal of Manufacturing Science and Engineering, 136(1), pp 1-14 (2013)

12. B. Erice, F. Gálvez, A coupled elastoplastic-damage constitutive model with lode angle dependent failure criterion, International Journal of Solids and Structures, 51(1), pp 93-110 (2014)

13. U. Kokturk, E. Budak, Optimization of broaching tool design, Intelligent Computation in Manufacturing Engineering, 4, 4 (2004).

14. A. Hosseini, H.A. Kishawy, Prediction of cutting forces in broaching operation, Journal of Advanced Manufacturing Systems, 12(01), pp 1-14 (2013)

15. S. Mandrile, G.C. Larroche, C. Vernault, G. Dessein, J. Denape, J.Y. Paris, Development of an in-house cutting forces simulation for fir tree broaching process, International Journal of Machining and Machinability of Materials, 15(1/2), 18 (2014)

16. Vogtel, P.; Klocke, F.; Puls, H. Modelling of process forces in broaching Inconel 718. Procedia CIRP, 8, pp 409-414 (2013)

17. S.V. Lukina, M.V. Krutyakova, O.P. Kupriyanova, P.F. Vyalkova, Optimal design broaching in microsoft Excel, Metal working and material science, 1, pp 24-26 (2010) 
18. S. Lukina, M. Krutyakova, Methodology for automated design of optimum cylindrical broach structures developed by total of criteria, Lecture Notes in Mechanical Engineering (2018).

19. S. Lukina, M. Krutyakova, S. Ivannikov, Designing spline broaches of optimal structure, MATEC Web of Conferences, 224, 01094 (2018)

20. S. Lukina, Formation of the system of the local indicators to assess the quality of the cutting tool at the stage of technical training of production, Metal Working and Material Science, 4, pp 43-50 (2015)

21. S.V.Lukina, Modeling of stresses-deformed state of inserted cutting tools during their production and operation, Avtomatizatsiya i Sovremennye Tekhnologii, 4, 27 (2001) 